\title{
Analysis of Body Composition and Specific Motor Movements of Junior Football Players
}

\author{
Izet Bajramovic ${ }^{1}$, Slavenko Likic ${ }^{1}$, Munir Talovic ${ }^{1}$, Haris Alic ${ }^{1}$, Eldin Jeleskovic ${ }^{1}$, Rasim Lakota ${ }^{1}$, Nedim \\ Covic $^{1}$ \\ 'University of Sarajevo, Faculty for Sport and Physical Education, Sarajevo, Bosnia and Herzegovina
}

\begin{abstract}
The aim of the research was to determine correlations between body composition and situational motor movements in football. The sample consisted of 22 respondents (16-18 years of age, $179.6 \pm 5.0 \mathrm{~cm}, 71.2 \pm 7.2 \mathrm{~kg}$ ), selected from junior football players that compete at the highest competition level for this category in Bosnia and Herzegovina. For the purposes of this research, a set of 7 variables was used. The Pearson correlation coefficient determined a medium high correlation between explosive strength of sprint type - running at $10 \mathrm{~m}$ with body weight $(r=.473 ; p<.05)$, and with body mass index $10 \mathrm{~m}(r=.576 ; p<.01)$. It can be concluded that more corpulent and havier players with optimum body mass index have better results in short sprint distance at $10 \mathrm{~m}$. The height of players does not make a significant contribution to the realization of specific footbal movements. Favorable body composition is not sufficient to explain the quality of the performance of specific motor movements in football.
\end{abstract}

Key words: Anthropometry, Sprinting, Specific Movements in Football

\section{Uvod}

Informisanost o nivou treniranosti sportista, te uzrocima i posljedicama takvog stanja, bitna je za njihov uspjeh. Poznato je da fudbaleri u igri ostvare veći broj kratkih sprinteva, te da primjenjuju različite načine vođenja lopte, pravolinijski i sa promjenom smjera kretanja. Struktura agilnosti s loptom je mnogo složenija u odnosu na takvo kretanje bez lopte (Sporiš, Milanović, Trajković, \& Joksimović, 2011). Brzina i eksplozivna snaga se smatraju preduslovom za uspjeh u omladinskom fudbalu (Reilly, Bangsbo, \& Franks, 2000), naglašavajući pritom ubrzanja na kratkim udaljenostima.

Visina i tjelesna težina su značajno povezane sa fizičkom izvedbom u slučaju mladih fudbalera (Mathisen \& Petersen, 2015). Ipak se sa sigurnošću ne može izolovati neka osobinu ili sposobnost koja donosi odlučujuću prednost u utakmici. Fudbaleri su tjelesno lakši od osoba koje žive sedentarnim načinom života (Popović, Akpinar, Jaksic, Matic, \& Bjelica, 2013), ali i niži u odnosu košarkaše, odbojkaše i rukometaše juniorske kategorije (Masanovic \& Vukasevic, 2009; Masanovic, 2018). Međutim, u sportovima gdje se traži velika brzina kretanja, nagla promjena pravca u velikoj brzini kretanja, grubi sudari sa protivnikom (fudbal i hokej), tjelesna visina ne samo da nije dominantna, nego je u određenoj mjeri i nepovoljna (Bjelica \& Fratrić, 2011).

Međusobni odnos tjelesne visine i težine (body mass index), te udio masne komponente (\% fat mass) u ukupnoj tjelesnoj masi, za trenere može biti važna informacija. Optimalne vrijednosti BMI-a mogu rezultirati u poboljšanju opšteg nivoa tjelesne i anaerobne snage (Nikolaidis, 2014). Fudbaleri imaju povoljan sadržaj mišića sa niskim nivoom tjelesnih masti (Popovic, Bjelica, Jaksic, \& Hadzic, 2014). Ipak, višak tjelesnih masti stvara nepotreban teret i umanjuje učinkovitost $u$ igri, te značajno narušava elemente tehnike mladih fudbalera (Nemčić, Fiorentini, \& Sporiš, 2018). Vrijednosti tjelesnih masti za vrhunske fudbalere su u prosjeku 7-12\%, te su niže nego u slučaju sedentarnih ljudi, ali su takođe više u odnosu na trkače u sportovima izdržljivosti (Shephard, 1999.). Pored optimalizacije voluminoznosti mišića, na količinu potkožnog masnog tkiva se može uticati dopunskim treningom (Conroy i Earle, 2000), i to djelovanjem u pravcu njene redukcije.

S obzirom da se takmičenja omladinskih liga organizuju shodno hronološkoj, a ne biološkoj starosti, često se pojedinci

\section{Montenegro}

Sport

\section{Correspondence:}

\section{S. Likic}

University of Sarajevo, Faculty for Sport and Physical Education, Patriotske lige 41, 71000 Sarajevo, Bosnia and Herzegovina

E-mail: slavenkolikic@gmail.com 
selekcionišu na temelju dominantnih morfoloških karakteristika. Opravdanost ovakvog postupka ima samo kratkoročne benefite koji mogu biti iskazani kroz stav da teži igrači imaju snažniji udarac po lopti i veću sposobnost sprintanja (Wong, Chamari, Dellal, Wislöff, 2009), međutim ovakav pristup ne može imati opravdanost sa gledišta dugoročnog procesa razvoja igrača.

\section{Metode}

Metodom slučajnog odabira sačinjen je uzorak ispitanika $(n=22)$ iz populacije fudbalera juniorske kategorije najkvalitetnijih takmičenja u Bosni i Hercegovini (prosječna starost $17,41 \pm 0,51$; prosječna visina $179.6 \pm 5.0 \mathrm{~cm}$; prosječna težina $71,2 \pm 7,2 \mathrm{~kg}$ ). Osnovni uslov za izbor ispitanika je igrački staž ( $>5$ godina), te $70 \%$ učešća u trenažnom i takmičarskom procesu za prethodnu godinu. Ispitanici su prije testiranja upoznati sa temeljnim odredbama Helsinške deklaracije, te su dobrovoljno pristali na testiranje, uz mogućnost odustajanja u bilo kojem trenutku. Golmani su izostavljeni iz uzorka ispitanika s obzirom da, po svojoj morfologiji i specifičnosti zadaća u igri, odstupaju od igrača u polju (S. Gil, J Gil, Ruiz, A. Irazusta, \& J. Irazusta, 2007; Gjonbalaj, Georgiev, \& Bjelica, 2018).

Testiranje je obavljeno u prvom pripremnom dijelu sezone, na umjetnoj travi. Istom je prethodilo standardizovano zagrijavanje (jogging 5 minuta, dinamičko/statičko istezanje 7 minuta i istrčavanja sa postepenim akceleracijama brzine do 90\% 3 minuta). Korišteno je ukupno 7 varijabli: visina tijela $(\mathrm{cm})$; težina tijela $(\mathrm{kg})$; indeks tjelesne mase (BMI); udio masne komponente (\%); 0-10m sprint (s); 0-30 vođenje lopte (s) i slalom vođenje lopte (s). Mjerenje visine je izvršeno pomoću antropometra (model Holtain, 610), a prema uputama Međunarodnog biološkog programa. Korištenjem digitalne vage Tanita (model BC-420MA) dobivene su vrijednosti tjelesne težine, tjelesnih masti i BMI-a. Tretirani testovi za procjenu situaciono-motoričkih sposobnosti u fudbalu zadovoljavaju metrijske karakteristike (Sporiš, 2007). Za mjerenje vremena je korišten sistem fotoćelija (model Micro-gate).

Za sve varijable izračunata je prosječna vrijednost (A.S.), apsolutno odstupanje ( \pm S.D.). K.S. testom je provjerena distribucija rezultata. Povezanost tretiranih varijabli je izračunata pomoću Pearsonovog linearnog koeficijenta korelacije. Statistička značajnost je prihvaćen na nivou $\mathrm{p} \leq 0,05$. Kvadriranjem dobivenih vrijednosti izračunati su koeficijenti determinacije koji ukazuju na dio zajedničke varijanse varijabli tjelesne kompozicije i specifično-motoričkih sposobnosti fudbalera.

\section{Rezultati}

Statistički značajne veze uočene su između tjelesne težine i eksplozivne snage tipa sprinta $10 \mathrm{~m}(\mathrm{r}=.473 ; \mathrm{p}<.05)$, te indeksa tjelesne mase i eksplozivne snage tipa sprinta $10 \mathrm{~m}(\mathrm{r}=.576$; $\mathrm{p}<.01)$

Tabela 1. Deskriptivni pokazatelji mjera tjelesne kompozicije i situaciono-motoričkih sposobnosti mladih fudbalera

\begin{tabular}{lcc}
\hline & Mean & S.D. \\
\hline Tjelesna visina $(\mathrm{cm})$ & 179.6190 & 5.04456 \\
Tjelesna težina $(\mathrm{kg})$ & 71.9455 & 7.14701 \\
Indeks tjelesne mase & 22.3136 & 1.77396 \\
Tjelesne masti (\%) & 6.2682 & 2.09043 \\
0-10m sprint (s), & 1.8727 & .10058 \\
0-30 vođenje lopte (s), & 4.5555 & .25220 \\
Slalom vođenje lopte $(\mathrm{s})$ & 9.7732 & 1.25304 \\
\hline
\end{tabular}

Legenda: Mean - aritmetička sredina; S.D. - standardna devijacija

Apsolutne vrijednosti dobivenih koeficijenata ukazuju na sne težine i eksplozivne snage tipa sprinta 10m, odnosno 33\% izsrednje jak intenzitet veze pozitivnog smjera. Koeficijenti deter- među indeksa tjelesne mase i eksplozivne snage tipa sprinta $10 \mathrm{~m}$. minacije ukazuju na zajednički dio varijanse od 22\% između tjele- Preostale tretirane varijable međusobno ne koreliraju ( $\mathrm{p}>.05)$.

Tabela 2. Linearni koeficijenti povezanosti između mjera tjelesne kompozicije i situaciono-motoričkih sposobnosti mladih fudbalera

\begin{tabular}{lccc}
\hline & 0-10m sprint (s) & 0-30 vođenje lopte (s) & Slalom vođenje lopte (s) \\
\hline \multirow{2}{*}{ Tjelesna visina $(\mathrm{cm})$} & -.122 & -.094 & -.195 \\
& .597 & .686 & .397 \\
Tjelesna težina $(\mathrm{kg})$ & $.473^{*}$ & .121 & .148 \\
& .026 & .592 & .510 \\
Indeks tjelesne mase & $.576^{* *}$ & .053 & .135 \\
& .005 & .813 & .549 \\
Tjelesne masti $(\%)$ & .422 & -.052 & .015 \\
& .050 & .817 & .948 \\
\hline
\end{tabular}

Legenda: * - Nivo statističke značajnosti $0.05 ;{ }^{* *}$ - Nivo statističke značajnosti 0.01

\section{Diskusija}

Prosječni rezultati varijabli za procjenu tjelesne kompozicije se mogu smatrati optimalnim za juniorski uzrast fudbalera (Tabela 1). Prosječni rezultati tjelesne visine i težine, te njihovog međusobnog odnosa, se podudaraju sa prethodnim istraživanjima (Masanovic, T. Bavcevic, \& I. Bavcevic, 2019), te bez obzira na slične vrijednosti indeksa tjelesne mase, može se konstatovati da sportisti juniorske kategorije imaju znatno niže vrijednosti udjela masne komponente u odnosu na nesportiste. Wong i sar. (2009) navode da vrijednosti BMI-a ne mogu 
biti dobar pokazatelj s obzirom da ukazuju na odnos tjelesne visine i težine, ali ne i sastava tijela kojeg čine masna i nemasna komponenta (mišići i skelet). Takođe, prosječni rezultati su blago veći u odnosu na rezultate mladih fudbalera (Arifi, Bjelica, \& Masanovic, 2019), odnosno niži u odnosu fudbalske klubove koji se takmiče u najkvalitenijim nacionalnim ligama Crne Gore, Kosova i Bosne i Hercegovine (Bjelica \& Gardasevic, 2019; Gardasevic, Bjelica \& Vasiljevic, 2019; Gardasevic, Bjelica \& Vasiljevic, 2019a).

Uočeni intenzitet i smjer veza između eksplozivne snage tipa sprinta sa tjelesnom težinom, odnosno indeksom tjelesne mase, potvrđuje rezultate dobivene u prethodnim istraživanjima (Brahim, Bougatfa, \& Mohamed, 2013; Mathisen \& Petersen, 2015). Posmatrajući sa stanovišta prakse, pojedine komponente tjelesne kompozicije mogu djelovati kao faktori koji olakšavaju ili otežavaju izvođenje različitih kretnih zadatka. Tjelesna visina, pogotovo u korelaciji sa težinom tijela, ima bitan uticaj na one varijable skokova i trčanja kod kojih, poslije savladavanja inertnosti tijela na početku izvođenja kretnog zadatka, postoji i dalje kretanje u istom pravcu (Kurelić, Momirović, Stojanović, Radojević, \& Viskić-Štalec, 1975). Kao takve mogu biti remeteći faktor u razvijanju početnog ubrzanja, koje se (Stroyer, Hansen, \& Klausen, 2004) dešava svakih 90 sekundi u fudbalskoj igri, pri čemu su (Barros, Valquer, \& Sant’anna, 1999.) udaljenosti u 49\% slučajeva kraće od 10 metara.

Odsustvo značajnije veze između nivoa masne komponente i testa za procjenu eksplozivne snage tipa sprinta se ne podudara sa nekim prethodnim istraživanjima (Gil i sar., 2007). Međutim, za očekivati je bilo, možda, utvrditi veći intenzitet povezanosti nivoa specifičnih motoričkih sposobnosti fudbalera u odnosu na tjelesnu kompoziciju, sagledavajući neka prethodna istraživanja (Wong i sar., 2009; Mathisen \& Petersen, 2015; Hyka, Bicoku, Mysliu, \& Cuka, 2017). Vjerovatno da za kvalitetnu realizaciju specifičnih kretnih struktura u fudbalskoj igri nije dovoljno biti sposoban samo brzo trčati, nego i posjedovati vještinu baratanja loptom. Za pretpostaviti je da osjećaj za kontrolu lopte u određenoj mjeri doprinosi njenom brzom vođenju. Pored tjelesnih i motoričkih odlika, Bjelica (2015) naglašava i nivo intelekta pri savladavanju složenog motoričkog kretanja.

Zbog učestalije trenažne aktivnosti kroz situacioni rad zasnovan na modelu igre (treninzi i utakmice), gdje se teži ka rješavanju fudbalskog problema, usvojenost tretiranih kretanja je možda na nižem nivou u odnosu na one koji se realno realizuju u uslovima stvarne igre, gdje su prisutni protivnici, saigrači, pravila, te ostali elementi fudbalske igre. Slabija utreniranost fudbalera je takođe moguća s obzirom na realizaciju testiranja u prvom dijelu pripremnog perioda. Kvalitet specifičnih kretnih struktura je vjerovatno izraženiji u toku takmičarskog perioda obzirom da su tada prisutni kako treninzi tako i utakmice sa visokim takmičarskim zahtjevima. Tereni sa umjetnom travom su mogli bitnije uticati na konačne rezultate istraživanja, s obzirom da je kontrola lopte otežana.

U konačnici se može zaključiti da teži igrači optimalnog indexa tjelesne mase ostvaraju zajedničko djelovanje pri sprintanju na kratkoj dionici. Visina tijela ne ostvaruje značajniji udio pri realizaciji specifičnih fudbalskih kretnji. Povoljna tjelesna kompozicija nije dovoljna za objašnjenje kvaliteta izvedbe specifičnih fudbalskih zadataka sa loptom.

\section{Acknowledgements}

There are no acknowledgements.

\section{Conflict of Interest}

The authors declare that there are no conflicts of interest.

Received: 12 February 2019| Accepted: 7 March 2019| Published: 19 April 2019

\section{References}

Arifi, F., Bjelica, D., \& Masanovic, B. (2019). Differences in Anthropometric Characteristics among Junior Soccer and Handball Players. Sport Mont 17(1), 45-49.

Barros, T., Valquer, W., \& Sant'anna, M. (1999). High intensity motion pattern analysis of Brazilian elite soccer players in different positional roles. Medicine and Science in Sports and Exercise, 31(S5), 260.

Bjelica, D., \& Gardasevic, J. (2019). Body Composition and Anthropometric Measures of Soccer Players, Champions of Montenegro and Bosnia and Herzegovina. In Book of Abstracts 16th Annual Scientifi c Conference of Montenegrin Sports Academy "Sport, Physical Activity and Health: Contemporary Perspectives" (73). Dubrovnik, Croatia: Montenegrin Sports Academy \& University of Montenegro.

Bjelica, D. (2015). Teorijske osnove tjelesnog i zdravstvenog obrazovanja. Podgorica - Nikšić: Fakultet za sport i fizičko vaspitanje UCG i Crnogorska sportska akademija.

Bjelica, D., i Fratrić, F. (2011). Sportski trening: teorija, metodika i dijagnostika. Nikšić: Fakultet za sport i fizičko vaspitanje.

Brahim, M., Bougatfa, R., \& Mohamed, A. (2013). Anthropometric and Physical Characteristics of Tunisians Young Soccer Players. Advances in Physical Education. 3(3), 125-130.

Gil, S., Gil, J., Ruiz, F., Irazusta, A., \& Irazusta, J. (2007). Physiological and Anthropometric Characteristics of Young Soccer Players According to Their Playing Position: Relevance for the Selection Process. The Journal of Strength and Conditioning Research 21(2), 438-45.

Gardasevic, J., Bjelica, D., \& Vasiljevic, I. (2019). Body Composition and Anthropometric Measures af Soccer Players, Champions of Bosnia and Herzegovina and Kosovo. In Book of Abstracts 16th Annual Scientifi c Conference of Montenegrin Sports Academy "Sport, Physical Activity and Health: Contemporary Perspectives" (74). Dubrovnik, Croatia: Montenegrin Sports Academy \& University of Montenegro.

Gardasevic, J., Bjelica, D., \& Vasiljevic, I. (2019a). Morphological Characteristics and Body Composition of Elite Soccer Players in Montenegro. International Journal of Morphology, 37(1), 284-288.

Gjonbalaj, M., Georgiev, G., \& Bjelica, D. (2018). Differences in Anthropometric Characteristics, Somatotype Components, and Functional Abilities among Young Elite Kosovo Soccer Players Based on Team Position. International Journal of Morphology, 36(1), 41-7.

Hyka, A., Bicoku, E., Mysliu, A., \& Cuka, A. (2017). The Association of Sprint Performance with Anthropometric Parameters in Youth Soccer Players. Sport Mont 15(1), 31-33.

Kurelić N., Momirović, K., Stojanović, M., Radojević, Ž. \& Viskić-Štalec, N. (1975). Struktura i razvoj morfoloških i motoričkih dimenzija omladine. Beograd: Institut za naučna istraživanja, Fakultet za fizičku kulturu.

Masanovic, B., Bavcevic, T., \& Bavcevic, I. (2019). Comparative study of anthropometric measurement and body composition between junior soccer and volleyball players from the serbian national league. Sport Mont, 17(1), 9-14. doi: 10.26773/smj.190202

Masanovic, B. (2018). Comparative study of anthropometric measurement and body composition between junior basketball and volleyball players from Serbian national league. Sport Mont, 16(3), 19-24.

Masanovic, B., \& Vukasevic, V. (2009). Diff erences of anthropometrical status on basketball and handball players in junior stature. Sport Mont, 6(1819-20), 576-82.

Mathisen, G., \& Petersen, S. (2015). Anthropometric factors related to sprint and agility performance in young male soccer players. Journal of Sports Medicine, 6, 337-342.

Nemčić, T., Fiorentini, F., \& Sporiš, G. (2013). Latentna struktura morfoloških varijabli na uzorku nogometaša kadeta. U Zborniku radova 22. ljetne škole kineziologa Republike Hrvatske. Poreč: Hrvatski kineziološki savez.

Nikolaidis, P.T. (2014). Weight status and physical fitness in female soccer players: is there an optimal BMI? Sport Sciences for Health, 10(1), 41-48.

Wragg, C.B., Maxwell, N.S., Doust, J.H. (2000.). Evaluation of the reliability and validity of a soccer-specific field test of repeated sprint ability. European Journal of Applied Physiology 83, 77-83.

Reilly, T., Bangsbo, J., \& Franks, A. (2000.). Anthropometric and physiological predispositions for elite soccer. Journal of Sports Sciences 18, 669-683 
Popovic, S., Akpinar, S., Jaksic, D., Matic, R., \& Bjelica, D. (2013). Comparative Study of Anthropometric Measurement and Body Composition between Elite Soccer and Basketball Players. International Journal of Morphology, 31(2), 461-7.

Popovic, S., Bjelica, D., Jaksic, D., \& Hadzic, R. (2014). Comparative Study of Anthropometric Measurement and Body Composition between Elite Soccer and Volleyball Players. International Journal of Morphology, $32(1), 267-274$.

Sporiš, G., Milanović, Z., Trajković, N., \& Joksimović, A. (2011). Correlation between speed, agility and quickness (SAQ) in elite young soccer players. Acta kinesiologica, 5(2), 36-41.
Sporiš, G. (2007). Efekti situacijskog polistrukturalnog kompleksnog treninga na morfološka, motorička, situacijsko-motorička i funkcionalna obilježja. Neobjavljena doktorska disertacija, Zagreb: Kineziološki fakultet Sveučilišta u Zagrebu.

Stroyer, J. Hansen, L. \& Klausen, K. (2004). Physiological profile and activity pattern of young soccer players during match play. Med. Sci. Sport Exerc. 36(1), 168-174.

Wong, P.L., Chamari, K., Dellal, A., \& Wislöff, U. (2009). Relationship between anthropometric and physiological characteristics in youth soccer players. The Journal of Strength and Conditioning Research, 23(4), 1204-1210. 